\title{
The Moderation Examination of ICT Use on the Association Between Chinese Mainland Students' Socioeconomic Status and Reading Achievement
}

\author{
https://doi.org/10.3991/ijet.v14i15.10494 \\ Ya Xiao, Jie $\mathrm{Hu}\left({ }^{\square}\right)$ \\ Zhejiang University, Hangzhou, China \\ hujezju.edu.cn
}

\begin{abstract}
This study explores the moderation effect of the information and communication technology (ICT) on the association between students' socioeconomic status and their reading achievement. In total, 9,596 samples of 15 years old from 268 schools in mainland China are drawn from the latest wave of the public database -- Program for International Student Assessment (PISA) 2015. This study applies the moderation model in multiple regression analysis to respectively analyze the moderation effect of 2 composite variables of students' ICT use, i.e., ICT use for schoolwork and ICT use for leisure. Two significant results are reported: (1) students' ICT use for schoolwork or for leisure can moderate the relationship between their socioeconomic status and their reading achievement; (2) the high-level ICT use for schoolwork or for leisure may narrow the gap in students' reading achievement caused by different socioeconomic status deduced from the buffering moderation effect of the moderating variables. These findings might provide insights to future studies in educational equality promotion, infrastructure construction and pedagogy improvement in reading education.
\end{abstract}

Keywords—Moderation effect, ICT use, reading achievement, PISA

\section{Introduction}

Educational equality is at a high priority in the informational-based society because it signifies a transformation in the effective educational system [1]. Reading education is taken as an essential link in equalizing educational opportunities [2]. A large number of efforts have been made by researchers, educators and policymakers; however, the reading achievement gap remains an alarming problem globally, which may be caused by factors at the student, family, school, and country levels [3]. By examining 30 international large-scale assessments over 51 years, Chmielewski (2017) finds that socioeconomic achievement gap has increased globally [4]. In particular, students' household economic, social and cultural status (ESES) is a key factor for the disparity in their reading achievement [5-7]. Thus, many countries or economies have integrated information and communication technology (ICT) into teaching and learning since ICT makes it possible to share educational resources and provide equal educational 
opportunities globally [8-9]. Although this implementation appears to provide an opportunity for low-performing readers to catch up with the high-performing readers, the OECD's report in 2015 suggested a nonsignificant correlation between ICT for educational purposes and students' improved reading literacy [10]. Therefore, this study aims to explore how ICT use moderates the relationship between students' socioeconomic status and their reading achievement.

\subsection{The interplay between students' socioeconomic status and their reading achievement in PISA}

The Program for International Student Assessment (PISA) is an international largescale assessment that has made a significant contribution to educational research and policy-making. PISA is a triennial assessment developed by OECD, which evaluates reading, science, and mathematics achievements among 15 -year-olds from participating countries/economies since 2000. Researchers have made great efforts to investigate the impact factors of students' reading performances in PISA. Among these factors, the socioeconomic status index derived from parents' education, parents' occupation, and the possessions at home seem to be a consistent cause for the reading achievement gap. Both the componential indicators and the composite index have been analyzed to examine the influence of students' socioeconomic status on their reading achievement. Barely no difference is detected in the variance explanation of the two models. For instance, based on Australian participants in PISA 2003, Polidano, Hanel and Buddelmeyer [6] found that students with low socioeconomic status fall behind those with high socioeconomic status by about $15 \%$ decrease in reading achievements, In PISA 2009, the index of socioeconomic status was positively correlated with students' reading achievement in all participating economies, in which a one-point increase in the socioeconomic status brings a score improvement varying from 25 (Mexico) to 52 (New Zealand) in OECD countries [11]. Meanwhile, this positive association was also testified in a PISA-plus study [7]. Moreover, a stable positive association between students' socioeconomic status and their reading performance has been found in a longitudinal study conducted in four European countries (France, Germany, Sweden and the United Kingdom) with proximal culture across five PISA waves (2000-2012) [5]. Therefore, abundant literature has confirmed that the higher the students' socioeconomic status is, the better their reading performances are.

\subsection{The association between students' socioeconomic status and ICT use}

Students' socioeconomic status not only relates to their academic achievement, but also associates with their ICT access and ICT use, as students coming from the advantaged and the disadvantaged socioeconomic background may respond to the same technology in different ways [12-13]. This problem has also been brought up in the issue of the digital divide. Traditionally, the digital divide describes a gap in terms of access to computers and connection to the Internet [14]. Previous studies show that higher socioeconomic status index predicts more ICT access and better ICT equip- 
ment; for example, students with higher socioeconomic status often have better digital media possession of ICT equipment and access in Brussels [15]. Gradually, with the broadband Internet access becomes prevalent and the digital devices become common, the focus of the digital divide issue shifts to the usage gap, i.e., differences in using ICT [16]. Researchers have found that students from different socioeconomic backgrounds usually have different degrees of ICT use. It finds that ICT use in the advantaged socioeconomic environment (urban areas) is $35 \%$ higher than those in the disadvantaged socioeconomic environment (rural areas) which is mainly influenced by students' ICT self-efficacy [17]. In addition, researchers tend to classify ICT use in more detailed ways in recent years. In particular, students' various ICT usage types, including commercial transaction, gaming, information, leisure, news, personal development and social interaction, are examined and classified into schoolwork and leisure purposes based on PISA 2015 ICT familiarity questionnaire [18].

\subsection{The association between students' socioeconomic status and ICT use}

In PISA, the impact of ICT on students' reading achievement remains controversial with different variables and methods utilized. In detail, where ICT is used has been identified in the previous literature as a consistent contextual factor. In PISA, two contexts of ICT use are identified, i.e., at school and at home. The results of the surveys on the use of ICT at school are complex. Specifically, an inverted U-shaped association is found between school ICT use and student' reading achievements, which indicates that the intense use of ICT at school may reverse the initial positive influence on reading achievement based on PISA participating countries in 2000 [19]. However, the influence of ICT use at school is recognized as negative on students' reading performance in PISA 2012 [20-21]. With regard to ICT is used at home, different purposes are taken into consideration, i.e., for schoolwork or for social entertainment. Specifically, the dimension of schoolwork includes browsing the Internet for essays, presentations, or for finding explanations, using e-mails for communicating with classmates on homework, downloading materials from school's website, etc.; the dimension of social entertainment involves collaborative gaming, accessing e-mail, and using social media. Some researchers have found that online activities at home for schoolwork increase students' reading achievements, while leisure activities decrease it [19-22]. In the meanwhile, some scholars later argue that ICT use for social entertainment at home positively influences students' reading performance [20].

\section{$1.4 \quad$ Research questions}

Based on the above-reviewed literature, the relationship between students' socioeconomic status, ICT use and reading achievement can be illustrated as follows: the association between students' socioeconomic status and their reading achievement indicates a reading achievement gap. Meanwhile, the relationship between students' socioeconomic status and their ICT use embodies a digital divide. Albeit an undefined relationship between students' ICT use and their reading achievement, the significant correlation between them has been confirmed in most studies. According to the theo- 
retical premise of formulated by Figure 1, this study aims to clarify this relationship by examining two research questions: (1) whether students' ICT use can moderate the relationship between their socioeconomic status and reading achievement? (2) if the research question 1 is proven true, what is the strength or direction of this moderation effect?

\section{$2 \quad$ Methodology}

\subsection{Participants}

The sample was retrieved from the PISA 2015 dataset (URL: http://www.oecd.org/pisa/data/2015database/), which is the latest PISA dataset released in December 2017. In PISA 2015, only four provinces, i.e., Beijing, Shanghai, Jiangsu and Guangdong (B-S-J-G), took the assessment in China. Therefore, 9,596 participants with balanced ratios of boys (52.48\%) and girls (47.52\%) from 268 schools in mainland China B-S-J-G regions were selected as samples in this study. Data of the samples' demographic information and ICT use outside school information were retrieved from PISA 2015 student questionnaire and ICT familiarity questionnaire using Python 3.5.

\subsection{The moderation effect analysis}

The moderation model: Conceptually, in multiple regression analysis, moderation occurs when the "boundary association" between two variables and "depends on a third variable" [23]. The third variable refers to the moderator variable, which can be either categorical (e.g., sex) or continuous (e.g., age). The moderator variable (M) affects the direction or strength of the relationship between the independent (X) and the dependent variables (Y). Figure 1 shows the simple moderation effect with a single moderator.

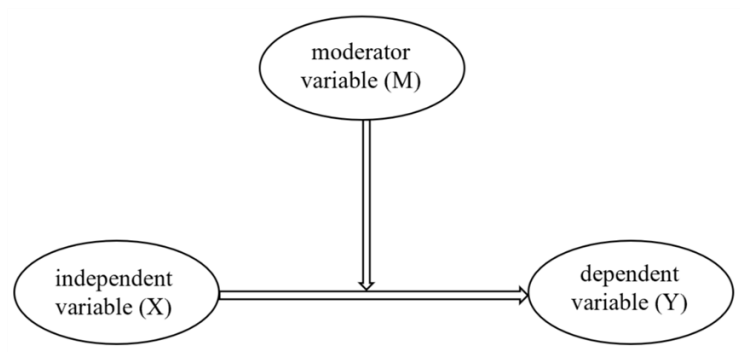

Fig. 1. The conceptual diagram of the simple moderation model with a single moderator adopted from@2013 Andrew F. Hayes, http://www.afhayes.com/

In this study, the independent variable was students' socioeconomic status (ESCS); the independent relationship was their reading scores, and the moderator variables 
were the ICT use indexes. In the ICT familiarity questionnaire of PISA 2015, ICT use indexes involve two contexts, i.e., at school and at home. Considering that the independent variable ESCS was a derived variable drawn from items mainly concerning students' household economic condition. In addition, only the ICT use at home indexes captured two purposes of ICT use, in particular, ICT use for school work (HOMESCH) and ICT use for leisure (ENTUSE), which was more comprehensive compared with the ICT use at school index. Therefore, students' ICT use at home indexes were selected as the independent variables. In the meanwhile, gender (ST004D01T) was included as a controlling variable. Table 1 illustrates the variables included in this moderation model.

Table 1. The description of variables in PISA 2015

\begin{tabular}{|c|c|}
\hline Variables & Description \\
\hline \multicolumn{2}{|r|}{ Independent variable } \\
\hline ESCS & Index of students' household economic, social and cultural status \\
\hline \multicolumn{2}{|r|}{ Moderator variables } \\
\hline HOMESCH & ICT use for schoolwork \\
\hline ENTUSE & ICT use for leisure \\
\hline \multicolumn{2}{|r|}{ Controlling variable } \\
\hline ST004D01T & Students gender \\
\hline \multicolumn{2}{|r|}{ Dependent variable } \\
\hline PVREAD & Students reading score \\
\hline
\end{tabular}

Note. Variables were obtained from PISA 2015 technical report [24]

Statistically, to quantify the moderation effect in multiple regression analyses, the interaction between the independent variable $(\mathrm{X})$ and the hypothesized moderator variable $(\mathrm{M})$ is added to the model which regresses the dependent variable $(Y)$ on the independent variable $(\mathrm{X})$. The moderation effect is measured by evaluating the parameter estimate for the interaction of the independent variable (X) and the moderator variable (M). Meanwhile, the association between the independent variable $(X)$ and the dependent variable $(\mathrm{Y})$, the moderator variable $(\mathrm{M})$ and the dependent variable (Y) must also be checked to assure the valid moderation effect.

In this study, if the moderation effect does exist, three hypotheses must be testified in the moderation statistical model. In detail, Hypothesis 1: Students' socioeconomic status $(\mathrm{X})$ is significantly correlated with their reading score (Y); Hypothesis 2: Students' ICT use for schoolwork or for leisure (M) is significantly correlated with the dependent variable (Y); Hypothesis 3: The moderation effect of students' ICT use for schoolwork or for leisure $(\mathrm{M})$ on the relationship between their socioeconomic status $(\mathrm{X})$ and their reading score $(\mathrm{Y})$ is significant. Hypothesis 1 is the premise for Hypothesis 3. Hypothesis 3 can be true even if Hypothesis 2 is false.

The equation for the moderation model is:

$$
Y_{i}=\left(b_{0}+b_{1} A_{i}+b_{2} B_{i}+b_{3} A B_{i}\right)+\varepsilon_{i}
$$

In this study, this equation is specified as:

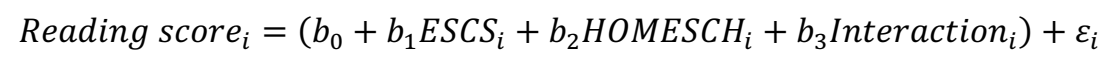




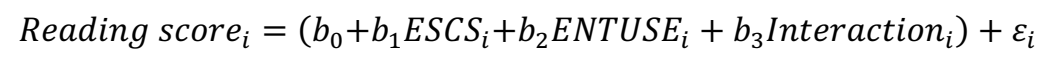

where

$\mathrm{Y}_{\mathrm{i}}$ refers to the dependent variable (reading score);

$\mathrm{b}_{0}$ refers to the intercept;

birefers to the relationship between students' reading scores and their socioeconomic statuses when they never use ICT for schoolwork (see equation 2) or for leisure (see equation 3 );

$\mathrm{b}_{2}$ represents the relationship between students' reading scores and their use of ICT for schoolwork (see equation 2) or for leisure (see equation 3 ) when they have zero socioeconomic status.

Procedures of data analysis: As for the data preprocessing, 246 observations from the original 9,841 observations were deleted because the majority of these observations were missing values. Meanwhile, the independent variables and the moderator variables were all weighed likelihood estimates based on the item response theory (IRT) scaling [24]. Therefore, there was no need to conduct weighting and normalization on the data for a second time.

As for the moderation effect analysis, this study followed a four-step analysis. The first step was to test the main effect of the predictors on students' reading score by simple linear regression so as to testify Hypotheses 1 and 2. The second step was to center the predictors, which avoids the situation when the interaction variable made the coefficients of the main predictors uninterpretable. The third step was to add the interaction variable (the independent variable*the moderation variable), a significant interaction would testify the existence of the moderation effect (Hypothesis 3 ). The fourth step was to delve deeper into the direction of this interaction, and simple slope analysis was conducted to work out the regression equations for the predictors, the independent variable, low- and high- levels of the moderator variable [25]. The simple slope analysis would be visualized in a plot to intuitively display the strength or direction of the moderation effect. In the past, these steps were to be conducted by typing in complex and troublesome syntax [26]. This study used the PROCESS tool developed by Andrew Hayes and his colleague Kristopher Preacher, which made it possible to access the complex syntax of the moderation model through a custom menu and a dialog box [27-29]. Compared with traditional regression tools, PROCESS is superior in the following aspects: (1) the predictors would be centered in advance by a simple click; (2) the interaction variable would be entered automatically, rather than be computed manually; (3) the simple slope analysis would also be done conveniently [30]. Essentially, the dependent variable would be regressed on the predictor at high- and low- levels of the moderator variable. In using PROCESS, 1 standard deviation above and below the mean value of the moderator variable was applied to distinguish these two levels. Therefore, it would be clear to see at which levels of the moderator variable the relationship between the independent variable and dependent variable is significant. 


\section{Results}

Hypothesis 1 was confirmed since students' socioeconomic status was significantly correlated with their reading achievement $(B=40.09, \mathrm{CI}=[38.43,41.74], t=47.53$, $p<0.001$ ), which laid the foundation for testifying Hypothesis 3 in the two moderation models with HOMESCH and ENTUSE as the moderator variable respectively. CI refers to the confidence interval.

When the moderator variable was students' ICT use for schoolwork (HOMESCH), Hypothesis 2 was also proved since ICT use for schoolwork was significantly associated with their reading score $(B=4.62, \mathrm{CI}=[2.76,6.49], t=4.86, p<0.001)$. Descriptive statistics in the final moderation model of HOMESCH for the outcome was shown in Table 2. It was found that the moderation effect was significant $(b=-2.4, \mathrm{CI}=[-4.01$, 0.80 ], $t=-2.94, p=0.003$ ), which suggested that Hypothesis 3 was confirmed. Namely, students' ICT use for schoolwork moderates the relationship between their socioeconomic status and reading achievement.

Table 2. The moderation model of students' ICT use for schoolwork of their reading score

\begin{tabular}{|l|l|l|l|l|}
\hline & \multicolumn{1}{|c|}{ b } & \multicolumn{1}{c|}{ SE B } & \multicolumn{1}{c|}{ t } & \multicolumn{1}{c|}{ p } \\
\hline Constant & $498.89 /[495.28,500.50]$ & 1.33 & 373.59 & $p<0.001$ \\
\hline ESCS (centered) & $41.08 /[39.44,42.72]$ & 0.84 & 49.03 & $p<0.001$ \\
\hline HOMESCH (centered) & $-4.62 /[-6.53,-2.70]$ & 0.98 & -4.73 & $p<0.001$ \\
\hline HOMESCH*ESCS & $-2.40 /[-4.01,-0.80]$ & 0.82 & -2.94 & $p=0.003$ \\
\hline gender & $24.10 /[20.47,27.72]$ & 1.85 & 13.03 & $p<0.001$ \\
\hline
\end{tabular}

Note. $\mathrm{R}^{2}=.21$.

As for the conditional effect of students' socioeconomic status on their reading scores at values of HOMESCH, it was found that (1) when the ICT use for schoolwork was at a low-level, there was a significant positive relationship between students' socioeconomic status and their reading score $(b=43.70, \mathrm{CI}=[41.17,46.24]$, $t=33.76, p<0.001)$; (2) when the ICT use for schoolwork was at a high-level, there was a significant positive relationship between students' socioeconomic status and their reading score $(b=38.46, \mathrm{CI}=[36.20,40.71], t=33.45, p<0.001)$. The nature of this moderation effect was further visualized in Figure 2.

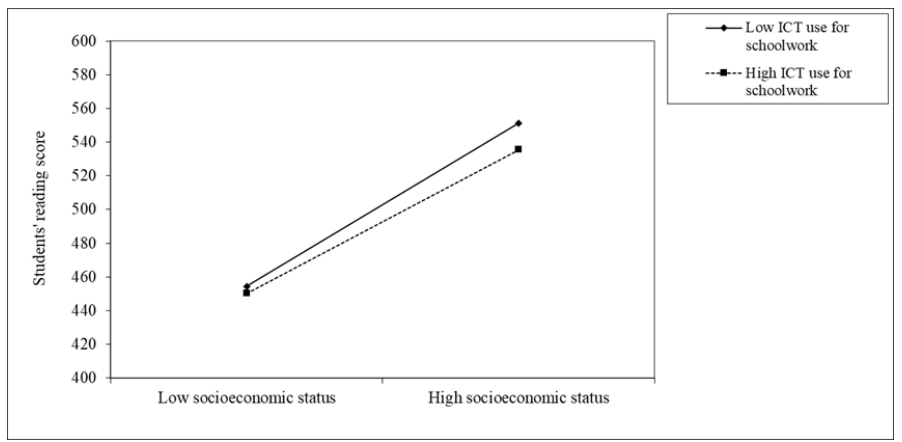

Fig. 2. The plot of the simple slope analysis for the moderator variable HOMESCH 
Note. The y-axis doesn't correspond to the exact reading score, but only reflects a trend. Therefore, the slope (b) should be the focus of discussion.

It was shown that with the increasing socioeconomic status, students' reading score improved, which proved the positive correlation between the independent variable and the dependent variable in Hypothesis 1. Meanwhile, whether in low- or high-level of ICT use for schoolwork, students' reading score improved with the increasing socioeconomic status. However, the high-level use of ICT use for schoolwork exerted a buffering effect on the positive correlation between students' socioeconomic status and their reading score.

When the moderator variable was students' ICT use for leisure (ENTUSE), Hypothesis 2 was not proved since ENTUSE $(B=-0.075, \mathrm{CI}=[-1.867,1.716], t=-0.082$, $p=0.934$ ) was not significantly correlated with their reading score. But it was found that the moderation effect was significant $(b=-3.57, \mathrm{CI}=[-5.09,-2.05], t=-4.61$, $p<0.001$ ), which still confirmed Hypothesis 3 . In this case, students' ICT use for leisure moderates the relationship between their socioeconomic status and reading achievement. Descriptive statistics in the final moderation model of ENTUSE for the outcome was shown in Table 3.

Table 3. The moderation model of students' ICT use for leisure of their reading score

\begin{tabular}{|l|l|l|l|l|}
\hline & \multicolumn{1}{|c|}{ b } & \multicolumn{1}{c|}{ SE B } & \multicolumn{1}{c|}{ t } & \multicolumn{1}{c|}{ p } \\
\hline Constant & $498.77 /[496.16,501.38]$ & 1.33 & 374.72 & $p<0.001$ \\
\hline ESCS (centered) & $41.03 /[39.41,42.64]$ & 0.82 & 49.77 & $p<0.001$ \\
\hline ENTUSE (centered) & $-5.71 /[-7.55,-3.86]$ & 0.94 & -6.06 & $p<0.001$ \\
\hline HOMESCH*ESCS & $-3.57 /[-5.09,-2.05]$ & 0.76 & -4.61 & $p<0.001$ \\
\hline Gender & $22.54 /[18.89,26.19]$ & 1.86 & 12.11 & $p<0.001$ \\
\hline
\end{tabular}

Note. $\mathrm{R}^{2}=.21$.

As for the conditional effect of students' socioeconomic status on their reading scores at values of ENTUSE, it was found that (1) when the ICT use for leisure were at a low-level, there was a significant positive correlation between students' socioeconomic status and their reading score $(b=45.09, \mathrm{CI}=[42.59,47.59], t=35.41, p<0.001)$; (2) when the ICT use for leisure were at a high-level, there was a significant positive relationship between students' socioeconomic status and their reading score $(b=36.96$, $\mathrm{CI}=[34.73,39.19], t=32.51, p<0.001)$. The nature of this moderation effect was further visualized in Figure 3. 


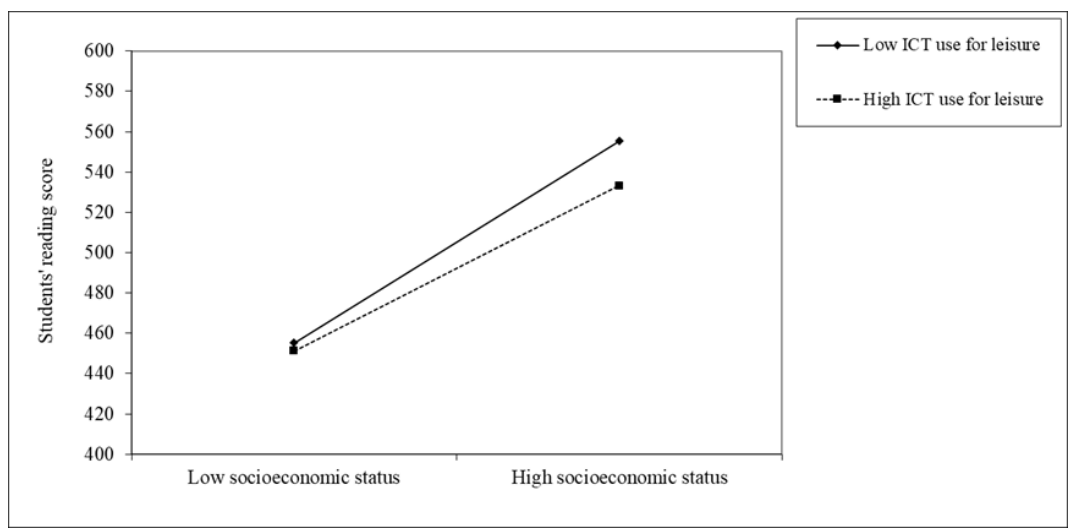

Fig. 3. The plot of the simple slope analysis for the moderator variable ENTUSE

The simple slope analysis on the moderator variable ENTUSE by PROCESS indicated a similar figure as what was produced on HOMESCH. High-level of ICT use for leisure also buffered the positive association between students' socioeconomic status and their reading scores.

\section{Conclusion and Discussion}

This study clarifies the moderating mechanism of ICT use between students' socioeconomic status and their reading achievement. Based on the moderation analysis using PROCESS developed by Andrew Hayes and his colleague Kristopher Preacher, it was found that students' ICT use for schoolwork or for leisure does moderate the relationship between students' socioeconomic status and their reading achievement. Additionally, deduced from the results of the moderation models, high-level of ICT use for schoolwork or for leisure would narrow the gap in students' reading achievement caused by different socioeconomic status. The results of ICT use for schoolwork support Lim and Jung's finding [31], which explains that students using ICT for schoolwork-related navigation tend to be more proficient to identify schoolworkrelevant statements and retrieve more useful information during reading activities. Meanwhile, as regards to ICT use for leisure, the result corresponds to previous research in which the use of ICT for entertainment purposes has a positive influence on students' reading achievement [20,32]. However, different from the current study that examines the indirect effect of students' ICT use on their reading achievement, these two research examine the direct effect of ICT use on students' reading achievement, while the former one is conducted among Turkish participants in PISA 2006 [32], and the latter one takes into consideration altogether 39 countries based on PISA 2012 dataset [20]. While the buffering effect of ICT use for schoolwork or for leisure is in contradictory with what has been discovered by Chiao and Chiu based on PISA 2012 data in East Asia [33]. In their study, students' ICT use whether for information retrieval or for social interaction should broaden the achievement gap in reading, mathematics and science, which might be caused by the inadequate guidance in using ICT 
before accessing students to ICT. The inconsistency trend reveals the trend of the moderation effect of ICT use on the relationship between the ESCS index and the reading achievement. The impact of ICT use on students' reading achievement gap caused by socioeconomic status changes from negative to positive from 2012 to 2015. In other words, instead of widening the reading achievement gap related to the socioeconomic status disparity, ICT use starts to show its positive side by narrowing this gap. One possible explanation might be the more integrated design of ICT supported learning and entertainment, the more interactive and engaging ICT environment, and the centrality of creativity in ICT-assisted teaching activities [34-36].

In general, ICT use is beneficial to students' reading achievement, especially to those from rather disadvantaged socioeconomic background. Currently, equal distribution of ICT is essential to educational equality, as it has become a ubiquitous educational tool tailored to students' new learning style [37-39]. As European Union has taken one of its most meaningful steps in integrating ICT into education through the eTwinning initiative [40], China is supposed to make more efforts to promote ICTassisted learning. In addition to its educational function, the entertainment functions of ICT may also increase students' ICT self-efficacy, alleviate students' academic stress and urge them to learn more efficiently $[32,41]$. As a qualified educator, it is time to take full advantage of ICT in teaching considering the deduced positive influence brought by ICT use for schoolwork in students' reading achievement improvement. Effective ICT-assisted teaching needs to guide students to apply technology as cognitive tools whether in class or outside of class rather than simply giving students the chance to use ICT [42-43]. Meanwhile, teachers should work with parents to guarantee the in-time monitoring since students' unstructured use of ICT for leisure might distract them from learning [22].

This study is not without limitations, as shown, the explained variance for the moderation model is $\mathrm{R}^{2}=0.21$. In the field of humanities and social sciences, this $\mathrm{R}^{2}$ value is typical because it is impossible to take into consideration all relevant variables to predict human behavior. Even if the $\mathrm{R}^{2}$ is low in this study, predictors are significantly correlated, which assures that the relationships underlying this moderation model still deserves to be explicitly analyzed [44]. In addition, this value is also common in previous studies on PISA. For instance, in the existing studies of regression analysis using PISA 2006 dataset [45], PISA 2012 dataset [46] and other dataset [47-50], the maximum $\mathrm{R}^{2}$ reached $0.310,0.239$ and 0.230 respectively. Therefore, in the future study, it is suggested to expand the scope of study by adding an offline interview with those participants if possible so as to take into considerations of more predictors of students' reading achievement.

\section{Acknowledgement}

The authors gratefully acknowledge the research project supported by the Central Universities Foundation of Zhejiang University 


\section{References}

[1] Xiao, Y., Hu, J. (2019). Assessment of optimal pedagogical factors for Canadian ESL learners' reading literacy through artificial intelligence algorithms. International Journal of English Linguistics, 9(4), 1-14. https://doi.org/10.5539/ijel.v9n4p1

[2] Leu, D. J., Forzani, E., Rhoads, C., Maykel, C., Kennedy, C. Timbrell, N. (2014). The new literacies of online research and comprehension: rethinking the reading achievement gap. Reading Research Quarterly, 50(1): 37-59. https://doi.org/10.1002/rrq.85

[3] Sung, Y. T., Tseng, F. L., Kuo, N. P., Chang, T. Y., Chiou, J. M. (2014). Evaluating the effects of programs for reducing achievement gaps: A case study in Taiwan. Asia Pacific Education Review, 15(1): 99-113. https://doi.org/10.1080/09645 292.2013.789482 https://doi.org/10.1007/s12564-013-9304-7

[4] Chmielewski, A. (2017). The global increase in the socioeconomic achievement gap, 19642015. CEPA Working Paper No.17-04: 1-41. Retrieved from Stanford Center for Education Policy Analysis, http://cepa.stanford.edu/wp17-04

[5] Lenkeit, J., Schwippert, K., Knigge, M. (2017). Configurations of multiple disparities in reading performance: Longitudinal observations across France, Germany, Sweden and the United Kingdom. Assessment in Education: Principles, Policy \& Practice, 25: 52-86. https://doi.org/10.1080/0969594X.2017.1309352

[6] Polidano, C., Hanel, B., Buddelmeyer, H. (2013). Explaining the socio-economic status school completion gap. Education Economics, 21(3): 230-247. https://doi.org/10.1080 109645292.2013 .789482

[7] Xiao, Y., Li, Y., \& Hu, J. (2019). Construction of the Belt and Road Initiative in Chinese and American media: A critical discourse analysis based on self-built corpora. International Journal of English Linguistics, 9(3), 68-77. https://doi.org/10.5539/ijel.v9n3p68

[8] Garba, S. A., Byabazaire, Y., Busthami, A. H. (2015). Toward the use of 21st century teaching learning approaches: The trend of development in Malaysian schools within the context of Asia Pacific. International Journal of Emerging Technologies in Learning, 10(4): 72-79. https://doi.org/10.3991/ijet.v10i4.4717

[9] Kim, H. S., Kil, H. J., Shin, A. (2014). An analysis of variables affecting the ICT literacy level of Korean elementary school students. Computers \& Education, 77: 29-38. https:// doi.org/10.1016/i.compedu.2014.04.009

[10] OECD. (2015). Students, Computers and Learning. Paris, France: OECD Publishing. https://doi.org/10.1787/9789264239555-en

[11] OECD. (2010). PISA 2009 Results: Learning to Learn-Student Engagement, Strategies and Practices. Paris, France: OECD Publishing. https://doi.org/10.1787/9789264083943$\underline{11-e n}$

[12] Bangaly, K. (2018). Modeling information and communication technology use continuance behavior: Are there differences between users on basis of their status? International Journal of Information Management, 38(1): 77-85. https://doi.org/10.1016/j.ijinfomgt 2017.08.007.

[13] Chen, J., Zhang, Y., Wei, Y., Hu, J. (2019). Discrimination of the contextual features of top performers in scientific literacy using a machine learning approach. Research in Science Education. https://doi.org/10.1007/s11165-019-9835-y

[14] Newhagen, J. E., Bucy, E. P. (2004). Routes to Media Access. Mahwah, NJ: Lawrence Erlbaum Associates, Inc.

[15] Mertens, S., D'Haenens, L. (2010). The digital divide among young people in Brussels: Social and cultural influences on ownership and use of digital technologies. Communications, 35(2): 187-207. https://doi.org/10.1515/COMM.2010.010 
[16] van Dijk, J. A. (2005). The Deepening Divide: Inequality in the Information Society. Thousand Oaks, CA: Sage.

[17] Liao, P. A. Chang, H. H., Wang, J. H., \& Sun, L. C. (2016). What are the determinants of rural-urban digital inequality among schoolchildren in Taiwan? Insights from BlinderOaxaca decomposition. Computers \& Education, 95(C): 123-133. https://doi.org/10.1016/ j.compedu.2016.01.002

[18] van Deursen, A. J., van Dijk, J. A. (2014). The digital divide shifts to differences in usage. New Media \& Society, 16(3): 507-526. https://doi.org/10.1177/1461444813487959

[19] Woessmann, L., Fuchs, T. (2005). Computers and student learning: Bivariate and multivariate evidence on the availability and use of computers at home and at school. CESifo Working Paper Series, 47(11): 339-347.Retrieved from: https://ssrn.com/abstract=619101

[20] Skryabin, M., Zhang, J. J., Liu, L., Zhang, D. H. (2015). How the ICT development level and usage influence student achievement in reading, mathematics, and science. Computers \& Education, 85: 49-58. https://doi.org/10.1016/j.compedu.2015.02.004

[21] Petko, D., Cantieni, A., Prasse, D. (2017). Perceived quality of educational technology matters: A secondary analysis of students' ICT use, ICT-related attitudes, and PISA 2012 test scores. Journal of Educational Computing Research, 54(8): 1070-1091. https://doi.org/ $10.1177 / 0735633116649373$

[22] Lee, Y. H., Wu, J. Y. (2013). The indirect effects of online social entertainment and information seeking activities on reading literacy. Computers \& Education, 67(C): 168-177. https://doi.org/10.1016/j.compedu.2013.03.001

[23] Hayes, A. F. (2013). Introduction to Mediation, Moderation, and Conditional Process Analysis: A Regression-Based Approach. New York, NY: The Guilford Press.

[24] OECD. (2017). PISA 2015 Technical Report. Paris, France: OECD Publishing. https://doi. org/10.1787/9789264270282-en

[25] Aiken, L. S., West, S. G. (1991). Multiple Regression: Testing and Interpreting Interactions. Newbury Park, CA: Sage.

[26] Field, A. (2013). Discovering Statistics Using IBM SPSS Statistics. London: Sage Publications Ltd.

[27] Hayes, A. F., Matthes, J. (2009). Computational procedures for probing interactions in OLS and logistic regression: SPSS and SAS implementations. Behavior Research Methods, 41(3): 924-936. https://doi.org/10.3758/brm.41.3.924

[28] Preacher, K. J., Hayes, A. F. (2004). SPSS and SAS procedures for estimating indirect effects in simple mediation models. Behaviors Research Methods, Instruments, and Computers, 36: 717-731. https://doi.org/10.3758/bf03206553

[29] Preacher, K. J., Hayes, A. F. (2008). Asymptotic and resampling strategies for assessing and comparing indirect effects in multiple mediator models. Behavior Research Methods, 40(3): 879-891. https://doi.org/10.3758/BRM.40.3.879

[30] Johnson, P. O., Neyman, J. (1936). Tests of certain linear hypotheses and their application to some educational problems. Statistical Research Memoirs, 1: 57-93.

[31] Lim, H. J., Jung, H. Y. (2019). Factors related to digital reading achievement: A multilevel analysis using international large-scale data. Computers \& Education. 133: 82-93. https://doi.org/10.1016/j.compedu.2019.01.007

[32] Gumus, S., Atalmis, E. H. (2011). Exploring the relationship between purpose of computer usage and reading skills of Turkish students: Evidence from PISA 2006. Turkish Online Journal of Educational Technology, 10 (3): 129-140. https://doi.org/10.1080/1475939X. $\underline{2011.588414}$ 
[33] Chiao, C., Chiu, C. H. (2018). The mediating effect of ICT usage on the relationship between students' socioeconomic status and achievement. The Asia-Pacific Education Researcher, 27(2): 109-121. https://doi.org/10.1007/s40299-018-0370-9

[34] Gros, B. (2016). The design of smart educational environment. Smart Learning Environments, 3(15): 1-11. https://doi.org/10.1186/s40561-016-0039-x

[35] Istenic, S. A., Turk, Ž., Zajc, M (2015). Transforming pedagogical approaches using tangible user interface enabled computer assisted learning. International Journal of Emerging Technologies in Learning, 10(6): 42-52. http://dx.doi.org/10.3991/ijet.v10i6.4865

[36] Hu, J., Wei, Y. (2019). The centrality of creativity: A new perspective on English language teaching. English Today, 35(2): 60-61. https://doi.org/10.1017/S0266078418000299

[37] Sharifullah, K., Gwo-Jen, H., Muhammad, A. A, Arshia, R. (2018). Mitigating the urbanrural educational gap in developing countries through mobile technology-supported learning. British Journal of Educational Technology, 50(2): 735-749. https://doi.org/10.1111/ bjet. 12692

[38] Wei, Y., Yang, Q., Chen, J., Hu, J. (2018). The exploration of a machine learning approach for the assessment of learning styles changes. Mechatronic Systems and Control, 46(3): 121-126. https://doi.org /10.2316/Journal.201.2018.3.201-2979

[39] Jin, Y., Li, B., Chen, N., Li, X., Hu, J. (2015). The discrimination of learning styles by Bayes-based statistics: An extended study on ILS system. Mechatronic Systems and Control, 43(2): 68-75. https://doi.org/10.2316/journal.201.2015.2.201-2666

[40] Papadakis, S. (2016). Creativity and innovation in European education. 10 years eTwinning. Past, present and the future. International Journal of Technology Enhanced Learning, 1(1): 279-296. https://doi.org/10.1504/IJTEL.2016.10001503

[41] Amornkitpinyo, T., Piriyasurawong, P. (2015). Causal relationship model of the information and communication technology skill affect the technology acceptance process in the 21 st century for undergraduate students. International Journal of Emerging Technologies in Learning, 10(1): 68-71. http://dx.doi.org/10.3991/ijet.v10i1.4185

[42] Chen, J., Hu, J. (2018). Enhancing L2 learners' critical thinking skills through a connectivism-based intelligent learning system. International Journal of English Linguistics, 8(6): 12-21. https://doi.org/10.5539/ijel.v8n6p12

[43] $\mathrm{Hu}, \mathrm{J}$. (2014). An analysis of the design process of a language learning management system. Control and Intelligent Systems, 42(1), 80-86. https://doi.org/10.2316/Journal.201. $\underline{\text { 2014.1.201-2534 }}$

[44] Neter, J., Kutner, M. H., Nachtsheim, C. J., Wasserman, W. (2012). Applied Linear Statistical Model. Washington, DC: American Statistical Association.

[45] Chiacchio, C. D., Stasio, S. D., Fiorilli, C. (2016). Examining how motivation toward science contributes to omitting behaviors in the Italian PISA 2006 sample. Learning and Individual Differences, 50: 56-63. https://doi.org/10.1016/j.lindif.2016.06.025

[46] Naumann, J., Sälzer, C. (2017). Digital reading proficiency in German 15-year olds: Evidence from PISA 2012. Zeitschrift für Erziehungswissenschaft, 20(4): 585-603. https://doi.org/10.1007/s11618-017-0758-y

[47] Cui, X. J., Yang, Q. X., Li, B., Tang, J., Zhang, X. Y., Li, S., Li, F. C., Hu, J., Lou, Y., Qiu, Y. Q., Xue, W. W., Zhu. F. (2019). Assessing the effectiveness of direct data merging strategy in long-term and large-scale pharmacometabonomics. Frontiers in Pharmacology, 10 (127): 143-156. https://doi.org/10.3389/fphar.2019.00127

[48] Chen, X., \& Hu, J. (2019). A corpus-based study of Hillary Clinton's and Donald Trump's linguistic styles. International Journal of English Linguistics, 9(4), 28-41. https://doi.org/10.5539/ijel.v9n4p28 https://doi.org/10.5539/ijel.v9n3p13 
[49] Chen, X., Yan, Y., \& Hu, J. (2019). A corpus-based study of Hillary Clinton's and Donald Trump's linguistic styles. International Journal of English Linguistics, 9(3), 13-22. https://doi.org/10.5539/ijel.v9n3p13

[50] Xiao, Y., Li, Y., \& Hu, J. (2019). Construction of the Belt and Road Initiative in Chinese and American media: A critical discourse analysis based on self-built corpora. International Journal of English Linguistics, 9(3), 68-77. https://doi.org/10.5539/ijel.v9n3p68

\section{$7 \quad$ Authors}

Ya Xiao is a Master's level student, supervised by Dr. Jie Hu, majoring in applied linguistics at the School of International Studies, Zhejiang University, Hangzhou 310058, China. Her research interests lie in computer-assisted English language learning, educational data mining, and second language acquisition.

Jie Hu (corresponding author), Ph.D., is a professor at the School of International Studies, Zhejiang University, Hangzhou 310058, China. She has been focusing on English language education for more than 10 years after her Ph.D. graduation from the University of Warwick, U.K. Her research interests include ICT-based English language education, second language acquisition, educational data mining and learning analysis. ORCID: http://orcid.org/0000-0003-2219-2587. E-mail: huj@zju.edu.cn

Article submitted 2019-03-17. Resubmitted 2019-06-13. Final acceptance 2019-06-15. Final version published as submitted by the authors. 